\title{
Visão de corpos mutilados: entre o real e o performativo
}

View of mutilated bodies: between the real and the performative

\section{Verônica Veloso}

Verônica Veloso

Doutoranda no Programa de Pós-Graduação em Artes Cênicas da Escola de Comunicação e Artes da Universidade de São Paulo (ECA-USP). Encenadora e performer, integra o Coletivo Teatro Dodecafônico

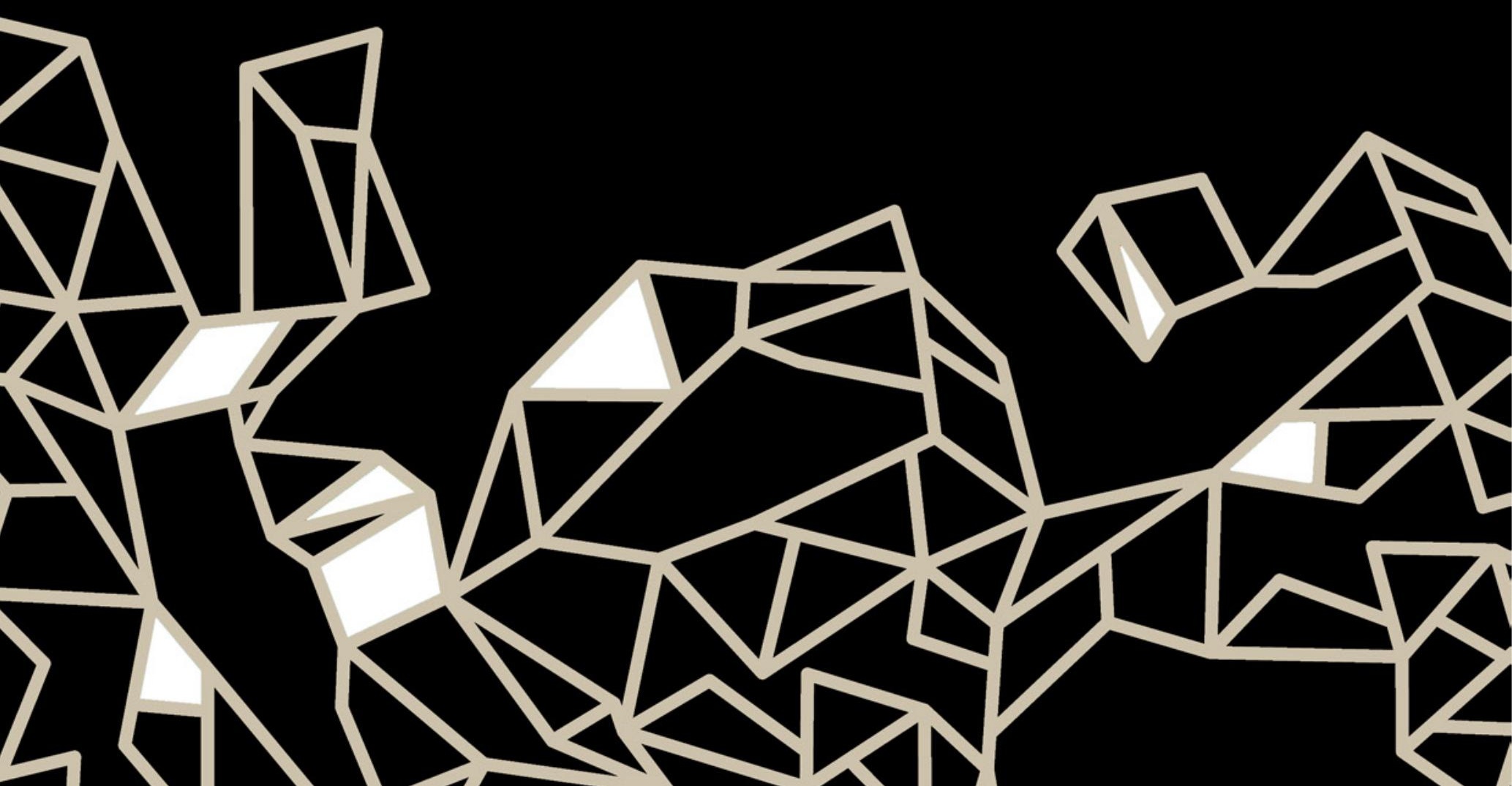




\section{Resumo}

A visão de corpos mutilados e mortos é cada vez mais frequente na cena teatral contemporânea, o que leva a questionar a pertinência de se confrontar o espectador com essas imagens do horror. Retomando teóricos como Didi-Huberman e Susan Sontag, o artigo propõe uma discussão sobre a associação da produção de imagens com a produção de imaginário. Duas encenações apresentadas em Paris logo após os atentados de novembro de 2015 são analisadas, observando-se aspectos documentais e biográficos que posicionam tais experiências entre $o$ real e o performativo.

Palavras-chave: Teatro performativo, Espectador, Corpo.

\section{Abstract}

Mutilated and dead bodies have been seen more frequently in contemporary theater scenes, which leads to question the pertinence of confronting the audience with these horror images. Based on Didi-Huberman's and Susan Sontag's theories, this article proposes a discussion of the association of image production with imaginary production. Two plays presented in Paris shortly after the November 2015 attacks are analyzed, observing documentary and biographical aspects that place such experiences between the real and the performative.

Keywords: Real, Performative theater, Viewer, Body.

Na segunda década dos anos 2000, a presença de imagens chocantes passa a ser notada com mais frequência na cena teatral. Em alguns casos, trata-se de documentos que se referem a fatos reais. Em outros, da representação de acontecimentos nos quais o corpo se revela moribundo, mutilado ou morto. Os espaços cênicos são cobertos de sangue, de violência e de guerra, pela exibição de corpos agonizantes. Algumas cenas chegam a ser difíceis de olhar. Didi-Huberman ressalta a importância de "arrancar" uma imagem dos campos de concentração, apesar de tudo. "Era preciso, custe o que custar, dar forma a esse inimaginável" (DIDI-HUBERMAN, 2003, p. 21, tradução da autora). Ele ressalta a relevância da produção de imagens para a produção de imaginário e cita depoimentos que levam a crer que quando não 
podemos imaginar um acontecimento, não acreditamos na sua existência. Hanna Arendt, citada pelo mesmo autor, afirma que os nazistas estavam convencidos do sucesso de seu empreendimento, pois ninguém poderia acreditar no que se passava dentro daqueles campos. Para confirmar essa intenção, bastaria observar a eficácia com a qual as provas do crime foram destruídas. Apagar os rastros de um momento histórico faz com que não haja certezas a respeito desse período.

No início de 2015, uma imagem publicada em alguns jornais do mundo provocou bastante polêmica. Um menino sírio-curdo à beira-mar de bruços, morto, sendo observado por um homem tomando notas, em uma praia na Turquia. O retrato desse menino [Aylan Kurdi] simboliza o êxodo de grande parte da população da Síria que, em busca de sobrevivência, submete-se a condições extremamente precárias para fugir do fogo cruzado entre os países dessa região. As discussões em torno do deslocamento de legiões de refugiados, transformando a Síria em um país em vias de desaparecimento, chegaram ao seu auge no momento em que a agência Reuters decidiu divulgar essa fotografia. A visão da criança morta foi internacionalmente discutida e condenada por uma parcela dos observadores, por mostrar algo em excesso. Segundo esse ponto de vista, trata-se de uma exposição obscena da morte alheia.

Gabriel Zacharias comentou em artigo publicado no jornal $O$ Estado de S. Paulo (5 set. 2015) que a força da imagem estava não no que ela revelava, mas justamente no que ela ocultava: a etnia da criança refugiada. Como seu rosto estava parcialmente encoberto, não era possível identificar seus traços étnicos. Sua pele não era negra, nem parda. Suas vestimentas poderiam ser usadas por qualquer criança ocidental, branca. A falta de elementos que posicionassem o garoto mais precisamente em relação a algum país representante de minorias fez com que a visão de seu corpo morto promovesse uma empatia generalizada. A comoção em torno da fotografia, segundo o pesquisador, "não se compreende se não atentarmos para o terrível esvaziamento que ela opera da alteridade de Aylan". Desse modo, seria menos a atrocidade presente na foto e mais o seu caráter genérico que tanto teria mobilizado a opinião pública. Interessa, no entanto, evocar esse fato na medida em que ele traz à tona a discussão acerca da pertinência de se tornar o horror visível. 
O teatro contemporâneo pode se valer igualmente de palavras e de imagens, sendo que a própria cena pode ser considerada imagética - um conjunto de imagens estáticas e em movimento. Então, por que confrontar o espectador com a visão do horror? Não se trata de reforçar a exibição exaustiva de imagens como acontece em algumas emissões televisivas sensacionalistas, que só reforçam a cultura do medo. Também não parece ter a mera intenção de estampar o trauma, chocar ou escandalizar. De que modo essas imagens que revelam o horror, que muitas vezes preferimos não ver, afetam os corpos que as observam? Divulgar imagens de mortos ou mutilados, sem mediação, sem distanciamento, é um ato brutal. Produzir ou difundir tais imagens seria um modo de fazer agir uma sociedade anestesiada?

O trecho a seguir apresenta uma pista para refletirmos acerca de dois espetáculos apresentados em Paris em 2015.

É preciso fazer com a imagem, com todo o rigor teórico, o que nós já fazemos, sem dúvida com mais facilidade (Foucault nos ajudou) com a linguagem. Porque em cada produção testemunhal, em cada ato de memória, ambas - linguagem e imagem - são absolutamente solidárias, não cessam de trocar suas lacunas recíprocas: uma imagem sempre vem onde parece falir a palavra, uma palavra sempre vem onde parece falir a imaginação. (DIDI-HUBERMAN, 2003, p. 39, tradução da autora)

O autor se refere à pertinência de se observar fotos dos campos de concentração como forma de compreender o que se passou. Segundo ele, para saber é preciso imaginar. Muitas pessoas, ao descreverem os campos de concentração, falavam em visões inimagináveis, e o autor reage justamente a esse inimaginável como dogma. Para ele, as fotografias não contam toda a verdade, mas são o seu vestígio. "O olho da história: sua tenaz vocação de tornar visível" (Ibid., p. 56, tradução da autora). O autor destaca a natureza essencialmente lacunar das imagens, assim como o real só pode se manifestar sob a forma de pontas, de pedaços de objetos parciais. As imagens não podem ser consideradas tudo, mas parece legítimo considerá-las como fragmentos, como rastros do real.

Não é a primeira vez que corpos mutilados ou mortos são expostos de tal maneira para a digestão do espectador. Porém, na atual circunstância, a referência direta (mas não intencional) aos atentados que ocorreram 
em Paris e o caráter documental das imagens que compõem as cenas exigem do espectador um exercício diferente. Outros tempos, outros confrontos a serem engendrados nos nossos imaginários e, por consequência, em nossos corpos, pois são eles que respondem a esse impacto. Por isso, as análises que se seguem levam em conta os corpos que recebem tais visões, corpos que não serão mais os mesmos, que não poderão deixar de ter visto.

A primeira encenação foi criada por Romeo Castellucci e apresentada no Festival de Outono em novembro de 2015: Le Metope del Partenone. Trata-se de uma performance no grande hall do La Villette, um espaço amplo e vazio, iluminado com luzes frias e sem nenhum aparato cenográfico que o modifique antes das cenas serem instaladas. Há apenas um projetor posicionado, de onde serão exibidos jogos de adivinhação: charadas elaboradas de maneira poética e cujas respostas serão sempre surpreendentes. Os espectadores permanecem de pé, podendo se deslocar e se posicionar onde quiserem. Seis situações são dispostas consecutivamente a partir da mesma estrutura: uma equipe caracteriza um performer, com sangue, bile, vômito, toda sorte de fluidos corporais, dependendo do acidente a ser representado. A situação é construída diante dos olhos do público. O modo de fabricação da cena é exposto e presenciamos a criação dos efeitos especiais para a representação de cada corpo agonizante. Assim que a equipe sai, o performer inicia sua encenação da dor: uma mulher sangra em decorrência de um acidente; a outra tem uma reação alérgica que provoca o inchaço do seu rosto e de suas mãos; um homem tem os órgãos expostos, depois de um grave ferimento abdominal; o outro queima boa parte do corpo com uma substância altamente inflamável; um senhor tem um ataque cardíaco, e uma jovem punk tem a perna explodida. As cenas se sucedem uma depois da outra, e todos, inevitavelmente, morrerão.

A ordem dos fatos é sempre a mesma: preparação do performer, encenação da dor, chegada de uma ambulância com paramédicos reais (que não são performers), cuidados para tentar reavivar o paciente e morte. Em seguida, a ambulância sai e uma charada é projetada na parede. Um exemplo desse jogo de adivinhação: 
A natureza, que decide cada coisa equitativamente, nos colocou, a mim e ao meu irmão, que somos gêmeos, nascidos de uma só mãe, de maneira simétrica. Eu estou separado dele por uma fronteira estreita formada de uma pequena colina, eu nunca o vi e ele nunca me viu. ${ }^{1}$

Após sua suposta morte, o performer se levanta, vai até a parede onde as frases são projetadas e permanece de pé até que a resposta ao enigma seja revelada. No caso acima, a resposta é: "o olho". Todas as situações dispostas nesse espaço poderiam acontecer no espaço público, no meio do fluxo da vida real. "Idealmente, é como estar na rua: estamos de pé, caminhamos, formamos círculos espontâneos em torno das ações”2. E há um elemento pinçado da vida real - a ambulância, cuja sonoridade sofre um processo de acumulação na medida em que as cenas progridem. Após os atentados de 2015, a ambiência sonora parisiense sofreu uma notável alteração. A presença de sirenes na paisagem da cidade passou a ser frequente. Para um habitante de São Paulo, a constância desse ruído já está incorporada no dia a dia da cidade. Entretanto, na capital francesa essa presença soa como um alarme, um estado de suspensão, de iminência da guerra: o estado de urgência. É sabido que tais sirenes nem sempre são ambulâncias, na maioria das vezes vêm dos carros da polícia que passaram a se posicionar de maneira mais ofensiva e visível (audível, nesse caso).

O fato é: não é só a repetição desse som, mas a representação do sangue e a iminência da morte que também ecoam como uma referência direta ao ocorrido. Na carta que Castellucci escreveu e destinou aos espectadores, ele explicou que a criação havia sido realizada há meses atrás para a feira de arte contemporânea de Basel, e que ela seria apresentada de maneira idêntica em Paris. O que o artista pretendia com essa carta era revelar o irreparável que o teatro representa, quando ele tem a infelicidade de se apresentar como um espelho atroz do que acabara de acontecer nas ruas dessa cidade. Ao se referir às "imagens difíceis de suportar, obscenas na sua exatitude inconsciente" (tradução da autora), o artista pede desculpas aos espectadores e os responsabiliza quanto a sua decisão: ficar ou partir.

1 Tradução da autora, a partir de foto realizada por ela no evento.

2 Trecho da carta de Romeo Castellucci (tradução da autora). $\mathrm{O}$ artista registrou sua própria voz lendo a carta, que foi ouvida antes das apresentações. Cópias dessas cartas foram distribuídas ao público na saída. 
Ao colocar em cena situações de acidente, fazendo uma referência direta ao contexto urbano, o encenador lança mão de uma estrutura recorrente na cidade. Nesse contexto, quando acontece um acidente, os passantes tendem a se organizar em roda, transformando uma fatalidade em espetáculo da vida real. Há um apelo voyeurista na encenação. Como o espectador está livre para se deslocar, é ele quem decide o quanto observa ou se decide não ver. Há quem tenha se recusado a ver, mantendo-se o tempo todo distante dos focos do acontecimento, mas também há relatos de espectadores que se sentiram mal e de outros que se entregaram completamente para a ação, vivendo junto com os atores as suas dores. Havia também aqueles que não se deixavam embalar pela interpretação duvidosa da dor e outros que analisavam os procedimentos adotados pelos paramédicos, questionando sua pertinência.

Dentre todos os mortos, um deles chamou atenção: uma jovem punk, com moicano cor de rosa, que embora performasse como os outros participantes, não tinha, de fato, uma das pernas. Seu ciclo foi o último a ser apresentado, o que gerou certo espanto em alguns espectadores, já habituados com o simulacro proposto. Ela chegou de muletas com a equipe de maquiadores que devia prepará-la, deitou-se no chão e, junto ao seu corpo real, foi posicionada uma meia perna mutilada, nas mesmas dimensões daquela que um dia integrou o seu corpo. Essa moça, por algum motivo muito íntimo, resolveu reviver repetidamente o acidente que modificou sua vida de forma definitiva. Foi curioso observar que em sua "interpretação" houve um lapso temporal antes de ela se dar conta de que sua perna estava realmente descolada de seu corpo. Há quem diga que em situações de dor extrema os acidentados quase não choram, não reclamam. Existe uma espécie de anestesia inconsciente que ajuda o corpo a lidar com a dor. Os outros performers mostraram imediatamente a dor. Apenas ela, que já possuía um corpo verdadeiramente mutilado, demorou alguns segundos para se dar conta da ausência da perna e, só então, gritou. Independente do aspecto do jogo do "ator", a presença desse corpo, sem mediação, sem truque, para além da representação, é que era impactante.

Parece relevante destacar que assim como houve o som repetitivo da sirene, ecoando nos corpos que presenciaram essas mortes performáticas, há uma frase que foi repetida para todos os moribundos: "mantenha os olhos abertos, fique com a gente!". Essa mensagem coincide com o final 
da carta de Castellucci: "nesse momento, me parece mais humano estar aqui. Estar aqui essa noite significa que é preciso estar presente e vivo, diante dos mortos" (tradução da autora).

Outra encenação que coloca em evidência a visão de corpos mutilados e mortos é a mais recente produção de Jacques Delcuvellerie, artista fundador do Groupov: L'impossible Neutralité. A encenação foi criada em parceria com Raven Ruëll, que ocupa sozinho a cena, acompanhado de uma profusão de imagens documentais relacionadas aos conflitos na Faixa de Gaza. Num palco despido de intervenções cenográficas, vemos cinco blocos altos dispostos lado a lado, de um material que sugere concreto armado, fazendo uma referência ao muro construído ao longo da fronteira de Israel. O quinto bloco, mais à direita, tem a ponta do alto quebrada: traço da terra devastada sobre a qual a encenação versa. Esses blocos são usados durante toda a apresentação como anteparo para a projeção de vídeos e fotografias, além de mapas, dados históricos e citações de textos que, infelizmente, não são ficcionais. Antes mesmo de a ação se estabelecer, quatro mapas que retratam a modificação do território palestino são projetados sobre os blocos. Eles datam de 1946, 1947, um período entre 1948 e 1967 e o mapa atual, retratando a perda progressiva do território palestino para o Estado de Israel.

A peça se inicia com fortes estrondos de bombardeios sobre Israel. Em seguida, um vídeo realizado logo após a explosão de três homens-bomba em Jerusalém (1997) é exibido. As imagens mostram corpos ensanguentados, pessoas em estado de pânico, um casal correndo com um bebê no colo, ambulâncias, além de muitos sons de sirenes. $\mathrm{O}$ vídeo se encerra com uma adolescente, que tenta consolar uma amiga e pede com um gesto para que o cinegrafista interrompa o registro daquele momento.

Nessa mesma ocasião, a filha de 13 anos de Nurit Peled-Elhanan foi morta, juntamente com duas amigas, a caminho de sua aula de dança. Duas conferências dessa professora universitária, que passou a integrar um grupo de pais enlutados, do qual participam israelenses e palestinos, são usadas na peça. A primeira delas é exibida como documento, em vídeo. A segunda é proferida ao final do espetáculo por Raven Ruëll, que a enuncia com alto teor de performatividade. $O$ modo pelo qual tais conferências foram apresentadas revela o movimento da própria encenação: do documental ao performativo. 
No primeiro momento, a figura de Nurit Peled-Elhanan é exibida como pessoa real, uma mãe que perdeu sua filha e que afirma, diante do Parlamento Europeu, que não gostaria de vingar a morte de sua filha, pois nenhuma mãe se sentiria vingada matando a criança de outra mãe. Tal figura provoca enorme empatia no público. Sua fala é firme, seu discurso, extremamente pacifista. Ela é consciente do contexto histórico do qual participa e faz um apelo para que se escutem o grito dessas crianças mortas e ajudem as mães a salvar seus filhos que ainda estão vivos.

Ao ouvir essa frase, o ator aplaude a projeção, fazendo coro com a audiência do parlamento. Uma nova fotografia é mostrada, dessa vez de uma criança loira de olhos fechados e semblante tranquilo, imagem que poderia ser um retrato de Raven Ruëll quando criança. No entanto, a voz de Jacques Delcuvellerie entra em cena para esclarecer o impasse. Ele afirma que a foto observada pelo público é de uma criança morta, não sem antes apresentar a origem belga do ator, sem antepassados judeus ou árabes. $O$ que a difere das demais crianças expostas até então é o fato de ela ter tido uma morte natural. Ele continua: a morte de uma criança escandaliza, ainda mais quando se sabe que tal morte poderia ser evitada. Uma sequência de fotografias de crianças palestinas mortas é projetada, sobre a qual pode-se ler diversas citações de israelenses autorizando e, inúmeras vezes, comemorando essas mortes.

Nesse ponto, o tema da peça é explicitado: a transgressão do tabu da morte de uma criança, seguida de discursos que a justifiquem, representa um sinal de alarme para todos. Segundo os artistas, duas imagens os mobilizaram nessa criação, produzidas após os bombardeios à Gaza no verão de 2014 . Uma foto registrada em Israel, retratando uma colina de onde israelenses assistiam aos bombardeios à Faixa de Gaza, sentados em cadeiras de praia, como se assistissem a um espetáculo. Esse local ficou conhecido como "colina da vergonha". E outra foto realizada por manifestantes pacifistas palestinos que, motivados pelo filme Avatar, de James Cameron (2009), pintaram seus corpos de azul na esperança de atraírem a atenção da imprensa internacional para as manifestações organizadas todas as sextas-feiras. Vale ressaltar que essa tentativa fracassou, pois poucas pessoas tiveram acesso a tais imagens.

A faixa de Gaza é um dos lugares mais populosos do mundo, e os bombardeios massivos nessa região já mataram 538 crianças e deixaram 3370 fe- 
ridas nos últimos anos. As que sobreviveram precisariam de acompanhamento psicoterapêutico para superar os traumas da guerra. Uma criança de 8 anos em Gaza já passou quatro vezes por bombardeios que destruíram grande parte do território. Nesse contexto, a idade média dos habitantes é de 17 anos. Esses dados são apresentados na peça juntamente com imagens realizadas por um drone que sobrevoa a região e mostra uma cidade inteiramente destruída. São bairros, ruas inteiras, edifícios parcialmente demolidos, por onde ainda caminham os sobreviventes de uma guerra estendida, cujas informações se confundem, tamanha a recorrência de conflitos noticiados nessa área.

Vê-se nessa profusão de imagens e dados o esforço dos artistas em analisar um contexto histórico no qual as informações se confundem. Se considerarmos a independência do Estado de Israel em 1948 como marco inicial dos conflitos entre Israel e Palestina, passando por algumas guerras nomeadas, como a Guerra do Sinai e a Guerra dos Seis Dias, por ocorrências como a crise do petróleo de 1973, o assassinato do primeiro ministro de Israel em 1995, os sucessivos bombardeios sofridos pelo povo palestino nas últimas décadas e os ataques de extremistas palestinos à Israel, pode-se dizer que esses povos vivem em guerra há mais de 60 anos. Com tantas idas e vindas, os dados a respeito desse território são nebulosos.

Essa busca por esclarecer o público a respeito desse contexto faz com que a primeira parte da peça seja apresentada na forma de conferência, sem nenhuma mediação teatral. Após a exibição dos primeiros vídeos, o ator assume o papel de um jornalista israelense judeu que dá palestras pelo mundo, denunciando declarações muito graves feitas por políticos e religiosos de extrema direita, que não seriam toleradas em nenhum país democrata. Segundo ele, ninguém fala sobre isso, mas tais declarações são fáceis de encontrar. Para tanto, ele não modifica sua ação, nem sua voz ou seu corpo, apenas passa a falar em inglês propondo um jogo com a "personagem", que é rapidamente abandonado quando ele volta a falar francês. Porém sua interpretação é menos relevante do que a longa lista de declarações terríveis que serão apresentadas, realizadas por rabinos, responsáveis por instituições de ensino e até pela atual primeira-ministra da justiça de Israel. Essas pessoas endossam o assassinato de bebês, o investimento em experiências científicas com palestinos presos e a morte de todas as mães palestinas. 
O ator revela uma série de declarações atribuídas a um sionismo sem reservas, como: "todos que não são judeus nasceram para nos servir"; "as mães devem morrer e as casas onde as serpentes foram criadas devem ser destruídas"; e "em Gaza, não há civil inocente." Numa busca desenfreada por "ganhar a guerra contra o mal", tais judeus ortodoxos encontram justificativas para o genocídio, defendem a raça e a pureza do sangue, condenando casamentos mistos e atacando palestinos como se fossem "animais, que não merecem viver". Ele mostra fotos de pichações nas ruas que incitam à violência contra os árabes, a intenção de apagar a faixa de Gaza, a favor do extermínio do povo palestino, além de jogos de videogame que convidam os jogadores a bombardear Gaza, uma região apresentada como um grande cemitério.

Delcuvellerie e Ruëll optam por apresentar rastros do real na primeira hora da peça, sobrecarregando a visão do espectador com imagens extremamente fortes. Apoiando-se numa estrutura de conferência-performance, eles não poupam o espectador ao revelar imagens de crianças mutiladas, ensanguentadas, além de uma foto na qual um homem mostra um meio corpo de criança, para que a câmera capture o nível de violência empregado nesses conflitos.

Aos poucos o ator se despede do papel do jornalista fazendo uma reverência a outros israelenses que pensam como ele e revela a dor que ele mesmo sente ao tratar desse assunto. De pés descalços, com a mesma barba do conferencista e vestindo uma camiseta azul, Ruëll coloca-se de joelhos e cita um escritor indiano que diz haver coisas que, uma vez que são vistas, já não podemos mais "desvê-las". Assim, ele inicia a segunda parte da peça, mais performativa, na qual ele se coloca pessoalmente, justificando o porquê de se voltar para tal tema. Com um gesto autobiográfico, ele conta a ocasião da morte de seu pai. De maneira poética, ele fecha os olhos para descrever a palidez do pai, cuja língua estava grossa e azul. Esse exemplo íntimo ajuda o público a se posicionar diante de imagens que não são fáceis de olhar e que, ao mesmo tempo, não podemos deixar de ver ou de ter visto. O impacto desse tipo de imagem modifica definitivamente o entendimento do mundo, ou, como diria George Didi-Huberman, "estamos diante do terrível que nos olha através dessas fotografias".

Ruëll assume a dor de cada corpo mutilado, como as crianças de Gaza que em atendimentos pós-trauma não tinham coragem de fechar os olhos. Segundo ele, os que mais sofrem, inevitavelmente falam menos. E sem tornar-se 
espetáculo - "quando tudo em torno de nós se apresenta como espetáculo"3 o ator é convincente, apresentando fatos provavelmente desconhecidos pela maioria dos presentes. Por alguns minutos, tenho a impressão de estar diante de um pastor que pretende me convencer de atrocidades e verdades dolorosas, carregadas de terror. É quando sou surpreendida por uma pluralidade de vozes citando vários nomes de pessoas mortas, enquanto Ruëll, tomado por uma dança-canto, grita: "eu não te esquecerei". Na tela aparecem as fotografias, os nomes e as datas de nascimento e morte; todos, sem exceção, menores de 13 anos. Aproveitando esse fluxo, o ator se pinta de azul, numa referência clara aos manifestantes palestinos. Ele amarra um lenço quadriculado na cintura e observa as fotos das crianças, abrindo e fechando os olhos, como se seus olhos tivessem se tornado o diafragma de uma câmera fotográfica. O turbilhão se encerra com seu corpo deitado no chão, entoando um canto triste e belo: uma elegia a todas essas mortes.

No último movimento da encenação, vemos o corpo do ator modificado pela visão dessas imagens extremas. Ele permanece, a partir de então, com os olhos fechados e as sobrancelhas arqueadas, como se processasse as imagens às quais foi confrontado. Por cima da pele pintada de azul, Ruëll veste um longo vestido, sem o lenço palestino e sem barba (só então notamos que se tratava de um adereço). O ator, nessa cena final, revela uma silhueta longilínea, pois está posicionado sobre um pequeno banco que o vestido encobre. A solução para sua caracterização é extremamente simples e sua aproximação do gênero feminino, delicada e potente. $O$ tempo todo, sabemos que se trata de um homem, portando um vestido, de pé sobre um banquinho. Essa posição o coloca em um estado de fragilidade e iminente desequilíbrio, que pode ser percebido pela alteração de sua voz. A fragilidade, no entanto, vem da dor do tema tratado, porque a mulher representada é gigante: Nurit Pelad-Elhanan, a mesma professora que figurava em um dos primeiros vídeos da peça. Ela é finalmente performada pelo corpo reconstituído de Ruëll, composto camada por camada, numa sobreposição de identidades. Assim, Nurit se materializa como uma mulher portadora de muitas vozes.

3 Depoimento do ator em conversa organizada por Josette Féral, com o diretor Jacques Delcuvallerie, após a apresentação do espetáculo no dia 10 de dezembro de 2015 na Maison des Métallos, em Paris. 
Apoiados nessa figura, Delcuvellerie e Ruëll conduzem esse documentário cênico percorrendo rastros da história em direção ao performativo. Esses cidadãos europeus, sem nenhuma relação de parentesco com os grupos envolvidos em tal conflito, porém profundamente tocados pela dor do outro, tomam para si o discurso de Nurit. Por meio das palavras dessa mulher-fortaleza - ela também vítima da violência do Estado -, convocam um laço de irmandade entre mulheres. Assim como Nurit Peled-Elhanan, o ator, metamorfoseado, cobre sua pele azul-palestina com o vestido transgênero e afirma que grita pelas pessoas que perderam seus filhos no campo de morangos ${ }^{4}$. Como mulher israelense, ela questiona porque uma palestina não foi convocada para falar em seu lugar no Parlamento Europeu, uma vez que são elas as que mais sofrem, não só com a violência, mas com o genocídio de seus filhos. Nessa altura, já não mais importa o sujeito que profere o discurso (se Nurit ou Ruëll), mas que tal discurso seja ouvido. Seus lábios encarnados salientam que não esperam, ou que não querem, que as muçulmanas tirem os seus véus. É que seus olhos encobertos por pálpebras cansadas já viram o bastante e nós já não somos mais os mesmos, pois não somos capazes de "des-ver".

Nas duas encenações analisadas, o espectador é exposto à visão de imagens da morte. Segundo Susan Sontag (2003), "desde quando as câmeras foram inventadas, em 1839, a fotografia flertou com a morte" (p. 24). No primeiro caso, as consecutivas mortes representadas por Castellucci não são fotografias, imagens estáticas, mas uma experiência de morte não só compartilhada, como reiterada. Desde a primeira situação apresentada, mediante as mais diversas reações por parte dos espectadores, resiste em alguns de nós uma esperança de que alguma vítima seja salva. Porém a opção do artista é enfatizar a morte. A morte como destino, como fato, como único fim possível. E a pergunta que ainda se coloca é: num sistema calcado em um fluxo incessante de imagens, por que o teatro também passa a confrontar o espectador com a visão da morte de modo tão cru, tão direto e sem mediações? Seria com a simples intenção de provocar choque? Um modismo? Um desejo de se equiparar a outras linguagens?

4 Uma referência a uma família palestina que perdeu quatro filhos enquanto colhia morangos. 
Assim como se afirmou que a guerra esgotou as palavras, pois elas já não suportariam mais os pensamentos, parece que o teatro, ao anexar o real, não poderia se furtar a expor corpos mutilados e mortos dentre as visões da contemporaneidade. Ao testemunhar o real, um século após o desenvolvimento das tecnologias de extermínio terem levado os homens a matarem em massa (em ataques aéreos e guerras nucleares), os espaços teatrais passam cada vez mais a mostrar e convocar reflexões sobre a morte. Se no primeiro exemplo o artista italiano nos faz presenciar certo número de mortes, independente das tentativas de salvamento, ele o faz pelo viés da experiência. São nossos corpos que se deparam com cada performer com o susto de estar diante de alguém em situação terminal. São nossos ouvidos que repetidamente aprendem a lidar com o impacto das sirenes, as mesmas que nos amedrontam diariamente nas ruas das grandes metrópoles do mundo. No segundo, o que o artista belga reitera são mortes documentadas por fotografias. Um meio que "só tem uma língua e que se destina potencialmente a todos" (Ibid., 2003, p. 21), mas que tragicamente dizem respeito a mortos invisíveis, embora amplamente documentados. O testemunho dessa dupla de artistas tem a ver com um tempo de incessante produção de imagens, de documentação excessiva, mas no qual a escolha do que é dado a ver passa pela mediação da grande mídia, que detém hoje o poder sobre a informação. Interessa a quem ver os mortos da Palestina? E os refugiados mortos por afogamento? Assim como não interessa ver os mortos das periferias dos grandes centros urbanos brasileiros, vítimas da polícia militar.

O investimento na visão dessas imagens deve ter por finalidade criar um nicho na consciência dos espectadores, implantar um desconforto, uma desordem na ordem estabelecida. Um modo de convocar as pessoas a olhar além das aparências, através de outros filtros. Quando os editores dos grandes jornais mundiais decidiram publicar a foto do menino curdo morto na praia, houve um apelo à empatia do lado ocidental do mundo. A visão desse menino possibilitou que uma camada de pessoas em situação privilegiada pudesse se colocar no lugar do outro, uma vez que aquele menino que não era negro nem aparentemente parte de nenhuma etnia desfavorecida poderia ser o fiIho de um deles. Em tempos de anestesia, os recursos utilizados para atrair o olhar do espectador vão ficando cada vez mais diversificados. E talvez por 
isso os artistas do teatro passem a insistir, em seus espaços restritos, nessas visões da morte. Não se trata de um recurso cujo efeito aciona as massas, pois as armas do teatro são de outra ordem. Entretanto, há uma guerra que se trava nos e pelos imaginários. À medida que as imagens da morte das crianças palestinas nos olham, elas complementam os dados divulgados na forma de palavras e modificam nosso olhar para essa parte do mundo. Não podemos mais "des-ver" essas imagens, pois elas integram a partir de então o nosso imaginário. Nas pequenas assembleias reunidas nos teatros, as experiências partilhadas têm efeito duradouro, podem ficar gravadas como cicatrizes, como peles azuis e sangue nos olhos, e são capazes de modificar permanentemente aqueles que se propuserem a encarar essas visões.

\section{Referências bibliográficas}

AVATAR. Direção de James Cameron. Produção de James Cameron e Jon Landau. Intérpretes: Sam Worthington; Zoë Saldaña; Sigourney Weaver; Stephen Lang; Michelle Rodriguez; Giovanni Ribisi; Joel David Moore e outros. Roteiro de James Cameron. Música de James Horner. Los Angeles: Twentieth Century Fox, 2009. 1 DVD (162 min), color. Produzido por Lightstorm Entertainment.

DIDI-HUBERMAN, G. Images malgré tout. Paris: Les Éditions de Minuit, 2003.

RANCIÈRE, J. A partilha do sensível. São Paulo: Editora 34, 2009.

SONTAG, S. Diante da dor dos outros. São Paulo: Companhia das Letras, 2003. ZACARIAS, G. O que não vimos. O Estado de S. Paulo, São Paulo, 5 set. 2015. Disponível em: <http://alias.estadao.com.br/noticias/geral,o-que-nao-vimos,1756884>. Acesso em: 6 dez. 2016.

Recebido em 06/12/2016

Aprovado em 06/12/2016

Publicado em DD/MM/AAAA 